\title{
Phytochemical Mediated Synthesis of Silver Nanoparticles using Musa paradisiaca Peduncle Latex and Its Photocatalytic and Antimicrobial Activity
}

\author{
B. Venkataramana, S. Siva Sankar, A. Saikumar, B. Vijaya Kumar Naidu* \\ Department of Materials Science \& Nanotechnology, Yogi Vemana University, Kadapa - 516 005, Andhra Pradesh, India.
}

\section{A R T ICLE DETAILS}

\section{Article history:}

Received 11 August 2018

Accepted 27 August 2018

Available online 14 September 2018

\section{Keywords:}

Phytochemicals

Silver Nanoparticles

Antimicrobial

Photocatalytic Activity

\begin{abstract}
A B S T R A C T
In the present work, green synthesis of silver nanoparticles (AgNPs) using a natural phytochemical agent has been described. The aqueous latex from Musa paradisiaca peduncle has been utilized as reducing as well as stabilizing agent. The formation of AgNPs was optimized by varying latex and $\mathrm{AgNO}_{3}$ concentrations and finally reaction time. Ultraviolet-visible spectroscopic analysis showed the surface plasmon resonance peak between 350 and $450 \mathrm{~nm}$ confirms the formation of silver nanoparticles. X-ray powder diffraction analysis revealed the crystalline nature of AgNPs, Fourier transform infrared spectroscopy analysis revealed that AgNPs were stabilized by polyphenols and other aromatics present in the Musa Paradisiaca peduncle latex, while X-ray energy dispersive spectroscopy confirms the metallic nature. The field emission scanning electron microscopy and high resolution transmission electron microscopy showed the spherical shape of the particles and size distribution of AgNPs measured by dynamic light scattering which are in the range of 40 to $50 \mathrm{~nm}$. The synthesized AgNPs showed photocatalytic activity on the degradation / removal of the methylene blue dye and the antimicrobial activity against Pseudomonas aeruginosa, Staphylococcus aureus and Klebseilla bacterial species.
\end{abstract}

\section{Introduction}

Nowadays, metallic nanoparticles (MNPs) received wide interest as a result of their strong optical properties [1] in the areas of energy, catalysis, medicine and water treatment, etc., [2]. Currently, various chemical and physical processes are used to prepare MNPs, which enable nanoparticles to be obtained with the special characteristics. However, these synthesis methodologies are often expensive, laborious and harmful to the environment. Therefore, there is a necessity for alternative strategies such as the production of profitable nanoparticles that are both safe and environmentally friendly. In recent years, many studies have been shown that plants, algae, yeasts, fungi and bacteria can transform inorganic metal ions into MNPs [3-5].

Among various MNPs, silver nanoparticles (AgNPs) became the main focus of intensive research because of their huge range of applications in areas like antimicrobials, catalysis, optics and biomaterial production. Properties of AgNPs depend on their morphology, size and distribution. Numerous approaches have been used for the synthesis of MNPs using plant extracts [6]. These approaches have several benefits over chemical, physical and microorganism methods because these require no hazardous chemicals, high energy and also the elaborate culturing method [7]. In Asian countries, phytochemical compounds from plants have been used as drugs in ancient time. As an example, it's better-known that tea leaf extract contains powerful antioxidants like polyphenols, which is a regular drink offers necessary health benefits [8].

Table 1 shows some of the recently reported literature on the synthesis of AgNPs using plant extracts such as Setaria italic husk, Grewiaflaviscences, Saccharomyces cerevisiae, Citrus lemon, Parkia speciosa Hassk, Acalypha hispida, Descurainia sophia, P. nigrum (Black pepper) leaves, Belgian endive, Cassia auriculata and flower extract, Nelumbonucifera, Alpiniakatsumadai seeds extract, Tamarind fruit extract etc., [9-21].

The literature survey showed that naturally obtainable agricultural wastes were not studied for the preparation of MNPs. A classic example of a natural material so abundantly available is the Musa paradisiaca latex which is obtained by cutting the peduncle after the ripening of bananas.
Musa paradisiaca popularly called banana is a perennial herb like tree, a major crop in several semitropical and tropical regions around the world. Different plant parts of Musa are used topically or orally as remedy in folk medicine and roots, pseudostem, leaves, peel and fruits of Musa plants have shown antimicrobial activity, antioxidant and anti ulcerogenic activity and also shows anti diabetic and hypoglycemic activity $[22,23]$.

Table 1 Represented recent publications of bio-synthesis of AgNPs

\begin{tabular}{|c|c|c|c|}
\hline Plant & Size (nm) & Shape & Reference \\
\hline Nelumbo nucifera seed extract & $10-15$ & $\begin{array}{l}\text { Quasi- } \\
\text { Spherical }\end{array}$ & {$[18]$} \\
\hline P. nigrum & $20-50$ & Spherical & {$[15]$} \\
\hline Alpinia katsumadai seed extract & 12.6 & $\begin{array}{l}\text { Quasi- } \\
\text { Spherical }\end{array}$ & [19] \\
\hline Tamarind fruit extract & 10 & $\begin{array}{l}\text { Cubic \& } \\
\text { Spherical }\end{array}$ & {$[20]$} \\
\hline Belgian endive & $19-64$ & $\begin{array}{l}\text { Quasi- } \\
\text { Spherical }\end{array}$ & [16] \\
\hline Cassia auriculata flower extract & $10-35$ & $\begin{array}{l}\text { Spherical } \\
\text { \&Triangle }\end{array}$ & [17] \\
\hline Cassia javanica. $L$ & 435 & Spherical & [12] \\
\hline Carissa spinarum & $20-50$ & Cubic & [13] \\
\hline Descurainia sophia & 35 & Spherical & [14] \\
\hline Setaria italica husk & 30 & Spherical & [8] \\
\hline Grewia flaviscences & 60 & Spherical & [9] \\
\hline Saccharomyces cerevisiae & 10 & Spherical & [10] \\
\hline Citrus limon & $10-30$ & Spherical & {$[11]$} \\
\hline
\end{tabular}

In this work, we synthesized AgNPs using latex of Musa paradisiaca peduncle as a reducing agent and the effective factors for its synthesis process by varying the metal ion and latex concentrations and time. AgNPs were characterized by Fourier transform infra-red spectroscopy (FTIR), X-ray diffractometer (XRD), particle size analyzer, field emission scanning electron microscopy (FESEM) and transmission electron microscopy (TEM). Antimicrobial and photocatalytic efficiency of the synthesized AgNPs are also studied. 


\section{Experimental Methods}

\subsection{Materials}

Silver nitrate $\left(\mathrm{AgNO}_{3}\right)$ was purchased from SD Fine Chemicals, Mumbai, India. Metheylene blue (MB) powder was purchased from Merck, Mumbai. The raw white latex was collected by cutting the green peduncle after separating fruits of the Musa paradisiaca plants near the place of Pulivendula, Kadapa (Dist.), Andhra Pradesh, India. White slurry latex was stored at $4{ }^{\circ} \mathrm{C}$ for further experiments. All solutions were prepared using double distilled water.

\subsection{Preparation of Latex Extract}

In a typical procedure, $1.75 \mathrm{~mL}$ of crude Musa paradisiaca peduncle latex was diluted in $49.25 \mathrm{~mL}$ of distilled water to make it $2.5 \mathrm{wt} \%$ solution and boiled at $80^{\circ} \mathrm{C}$ for 15 mins. Using whatman No.1 filter paper the latex was filtered and stored at $4{ }^{\circ} \mathrm{C}$ for later use.

\subsection{Qualitative and Quantitative Estimation of Phytochemicals}

The qualitative and quantitative analysis of Musa paradisiaca peduncle latex was performed by the following methods of Arunachalam et.al. [24, $25]$ to determine the presence of phytochemical compound such as triterpenes, alkaloids, flavonoids, phenolics, saponins, and tannins [2628]. The quantitative analysis of the total phenolic content was measured using the method of Ciesla and Mariita et.al [29, 30] whereas flavonoids were estimated using colorimetric method of aluminum chloride. Gallic acid has been used as a standard for the analysis of total antioxidant capability.

\subsection{Synthesis of AgNPs using Musa paradisiaca Peduncle Latex}

AgNPs were prepared by adding $2.5 \mathrm{~mL}$ of latex to $47.5 \mathrm{~mL}$ of $1 \mathrm{mM}$ $\mathrm{AgNO}_{3}$ solution and the reaction mixture was kept under dark conditions at room temperature in a laboratory environment. The reducing process of $\mathrm{Ag}^{+}$ions to AgNPs was monitored by measuring UV-Vis spectra at regular time intervals. The effect of $\mathrm{AgNO}_{3}$ concentration (1-5 mM) was studied keeping the latex concentration constant $(2.5 \%)$ and the effect of the latex concentration was varied $(2.5 \%, 5 \%, 7.5 \%$ and $10 \%)$ maintaining the concentration of $\mathrm{AgNO}_{3}$ constant at $1 \mathrm{mM}$. Once the reduction was complete, the AgNPs were isolated at $8000 \mathrm{rpm}$ for 20 minutes in Remi (C24 plus modal) centrifuge and then washed with double distil water three times under centrifugation. Finally, the silver nanoparticles were dried and stored.

\subsection{Characterization of Synthesized AgNPs}

The formation of AgNPs was monitored using UV-Vis spectrophotometer (Lab India, Model 3092, Mumbai). The X-ray diffraction technique (XRD) is used to analyze the crystalline nature of synthesized Ag particles. The XRD pattern of dried AgNPs was recorded on Rigaku mini 600 using $\mathrm{Cu} \mathrm{K} \alpha$ radiation X-ray diffractometer. Dried AgNPs were grinded with $\mathrm{KBr}$ to make pellet and Fourier transforms infra-red spectroscopy (FTIR) spectra was recorded using PerkinElmer spectrophotometer. Field emission scanning electron microscopy (FESEM) with energy dispersive X-ray analysis (EDAX) was carried out on SUPRATM with co-relatively microscope SEM machine. Dried powdered sample was placed on the SEM grid and the images were taken for size and morphology and EDAX spectra were also taken along with SEM images to find out the chemical composition. TEM sample was prepared by placing a droplet of aqueous dispersion on 200 mesh copper grids coated with carbon and dried at ambient conditions for 10-12 hours. TEM images were collected using a JEOL 3010 at $200 \mathrm{kv}$ microscopy. The average size and distribution was measured using Zeta Sizer model Nano-S90 (Malvern U.K) using nanoparticles dispersion.

\subsection{Antimicrobial Activity}

Antimicrobial efficiency of synthesized AgNPs was examined against Pseudomonas aeruginosa, Staphylococcus aureus, Klebseilla and Escherichia coli microbial species. This was carried out with $24 \mathrm{~h}$ active cultures of the selected strains of bacteria by disk diffusion method [9]. The four tested organisms are swiped over the agar medium with help of sterilized spreader, and the silver nanoparticles containing disks were kept over the medium using sterile forceps. AgNPs disks were prepared separately at different concentrations $(10,20$, and $30 \mu \mathrm{L})$ using $1 \mathrm{mg} / \mathrm{mL}$ aqueous dispersion and 1\% streptomycin solution (antibiotic) was used as control .The plates were incubated at $35^{\circ} \mathrm{C}$ for $24 \mathrm{~h}$, finally the zone of inhibition zone (ZoI) around the well was measured.

https://doi.org/10.30799/jnst.151.18040511

\subsection{Photocatalytic Activity of Synthesized AgNPs}

Photocatalytic activity of synthesized AgNPs were studied for the degradation of methylene blue (MB) dye prepared in an aqueous medium. The photocatalytic degradation reaction was carried out under sunlight with continuous agitation. In a typical experiment, $15 \mathrm{mg}$ of AgNPs catalyst was loaded in $50 \mathrm{~mL}$ of $20 \mu \mathrm{g} / \mathrm{mL}$ aqueous $\mathrm{MB}$ solution. The average ambient temperature during the experiment was found to be around $30^{\circ} \mathrm{C}$ at our university. The intensity of sunlight is around 80,000 flux. At regular time intervals, $2 \mathrm{~mL}$ of suspension were pipetted and centrifuged at 5,000 rpm for 10 min to eliminate the catalyst and the absorbance was measured using UV-Vis spectrophotometer.

\section{Results and Discussion}

The preliminary quantitative and qualitative analysis of aqueous latex confirms the presence of phenolics, flavonoids, alkaloids, tannins, terpenoids and sterols as shown in Table 2. Phenolic, terpenoids and flavonoids compounds shows a broad range of biological activity, such as antioxidants, inhibition of lipid per-oxidation etc. The activity of the compounds depends mainly on their molecular structure and position of functional groups, such as the hydroxyl.

Table 2 Estimated quantity of phytochemical compounds present in Musa paradisiaca latex extract

\begin{tabular}{ll}
\hline Phytochemical Compounds & $\mu \mathrm{g} / \mathrm{g}$ \\
\hline Phenolics & $102.59 \pm 0.6$ \\
Terpenoids & $39.48 \pm 1$ \\
Alkaloids & $0.045 \pm 0.0002$ \\
Tannins & $0.035 \pm 0.0001$ \\
Flavonoids & $26.55 \pm 0.3$ \\
ABTS & $85.76 \pm 0.25$ \\
\hline
\end{tabular}

The size, shape, concentration, agglomeration state and refractive index near the surface of MNPs are responsible for the observed optical properties, hence, UV-Vis spectroscopy becomes an important tool to identify, characterize and study the MNPs [31]. After the addition of latex to the $\mathrm{AgNO}_{3}$ solution, a visible color change was observed $[9,10]$ and the intensity of the color increased with reaction time, the latex and silver nitrate concentrations. Finally, a dark brown transparent dispersion was formed (Fig. 1) which suggested the formation of AgNPs. The presence of phytochemical compounds such as phenols, alkaloids, terpenoids, tannins, flavonoids and antioxidants in latex could be involved in reducing $\mathrm{Ag}^{+}$ions and stabilization of formed AgNPs during the reaction [32].

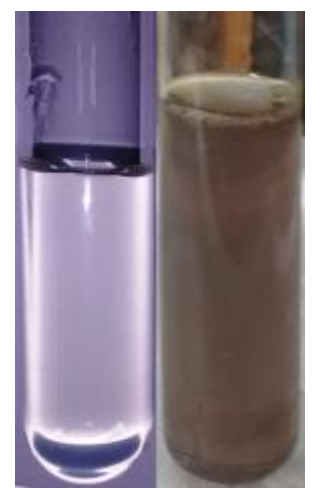

Fig. 1 Visual observation of change in color of the solution during the reduction reaction

The green synthesis of AgNPs has been studied using $1 \mathrm{mM}$ aqueous solution of $\mathrm{AgNO}_{3}$ with different concentrations of latex and the results are shown in Fig. 2. The characteristic absorption band of surface plasmonic resonance (SPR) at 360-450 $\mathrm{nm}$ was observed. The absorbance of this band increases with increasing the concentration of the latex to $5 \%$ and further increase in concentration decreases the absorbance. The increase in the concentration of the latex obviously increases the percentage of AgNPs formation because of availability of more reducing agents. However, the observed decreases in the absorbance of the characteristic band greater than $5 \%$ concentration of the latex could be due to the formation of larger aggregates.

A concentration variation study of silver nitrate (1-5 nM) using $2.5 \%$ of latex as a constant was studied and results are presented in Fig. 3. As the concentrations silver ions increases the intensity of the SPR band between 360-450 $\mathrm{nm}$ also increases suggest that more and more quantity of silver particles formed [32]. Fig. 4 shows the UV-vis spectra of AgNPs 
synthesized at various time durations. The characteristic SPR band between 360-450 nm of AgNPs appeared within 10 min of reaction time and the intensity of the band increases with increase in time.

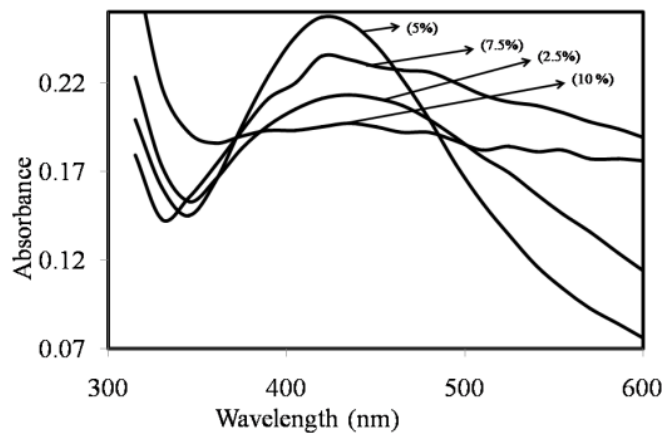

Fig. 2 UV-Vis spectra of silver nanoparticle dispersions with varied concentration $(2.5 \%, 5 \%, 7.5 \%$ and $10 \%)$ of latex

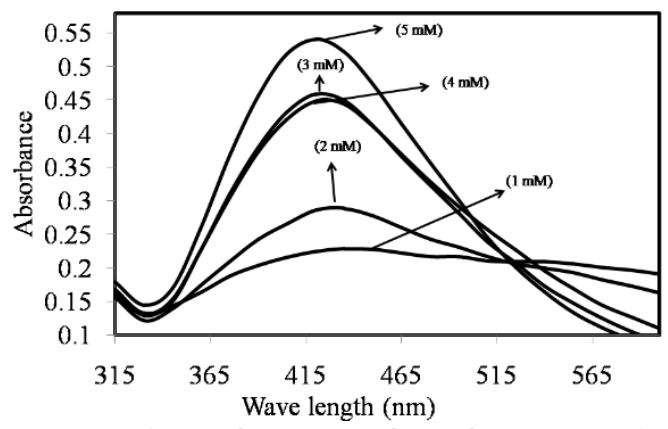

Fig. 3 UV-Vis spectra of AgNPs dispersions with varied concentration (1, 2, 3, 4 and $5 \mathrm{mM}$ ) of $\mathrm{AgNO}_{3}$ solutions

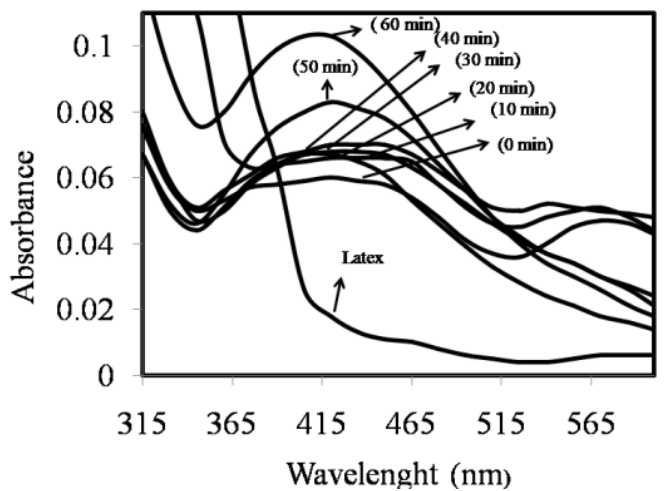

Fig. 4 UV-Vis spectra of AgNPs formation at different time intervals with $2 \mathrm{mM}$ of $\mathrm{AgNO}_{3}$ and $2.5 \%$ of latex

From all the above variations studied, it was decided to use $2 \mathrm{mM} \mathrm{AgNO}_{3}$ and $2.5 \%$ latex concentration and $50 \mathrm{~min}$ of reaction as standard for all further studies [33].

XRD pattern of AgNPs displayed in Fig. 5 showed the Bragg's reflections with $2 \theta$ values $38.15^{\circ}, 44.31^{\circ}, 64.48^{\circ}$ and $77.42^{\circ}$ lattice planes in the diffractogram. These values could be indexed to (111), (200), (220) and (311) planes of the face centered cubic (FCC) structure, which confirms the crystallinity. The data obtained were compared with the database of the joint committee on powder diffraction standards (JCPDS file No. 040783 ) which is in good agreement with the standard values [31, 32].

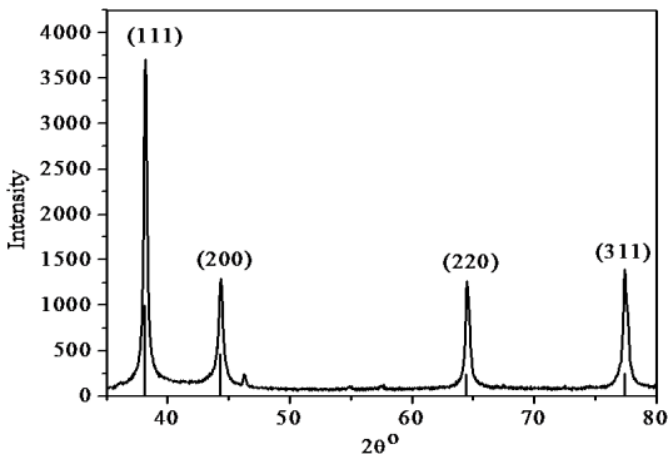

Fig. 5 XRD pattern of synthesized AgNPs by using Musa paradisiaca peduncle latex
The FTIR spectra of AgNPs synthesized using latex were presented in Fig. 6. The band at $3430.91 \mathrm{~cm}^{-1}$ represents to the $0-\mathrm{H}$ groups and also the H-bonded alcohols and phenols of latex. The band at $2933.36 \mathrm{~cm}^{-1}$ represents to $\mathrm{C}-\mathrm{H}$ vibrations indicates the presence of alkanes. The band at $2417.14 \mathrm{~cm}^{-1}$ and $1613.28 \mathrm{~cm}^{-1}$ represents and primary amines groups present within the latex. The band at $1383.16 \mathrm{~cm}^{-1}$ indicates $\mathrm{C}-\mathrm{H}$ rock alkenes and at $1105.72 \mathrm{~cm}^{-1}$ to that of $\mathrm{C}-0$ stretching carboxylic acids, esters, alcohols, and ethers. This analysis provides evidence for the presence of metabolites and proteins such as terpenoids with functional groups of ketones, alcohols, aldehydes, phenols, alkaloids, tannins, flavonoids and carboxylic acids, which act as reducing agents and help to increase stability of the synthesis AgNPs [31,32].

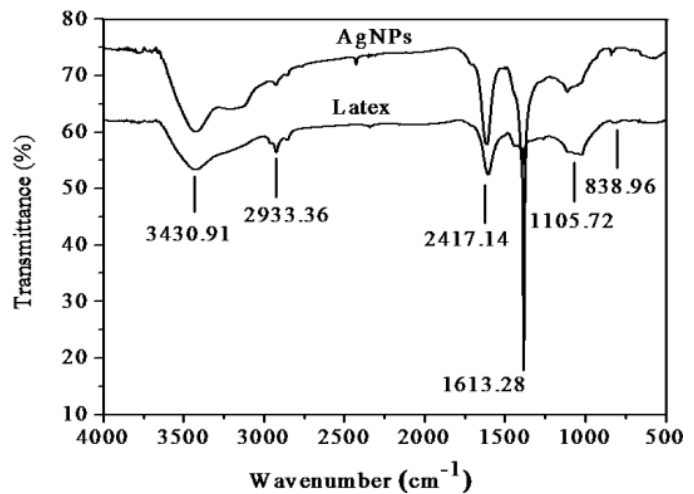

Fig. 6. FTIR spectra of synthesized AgNPs by using Musa paradisiaca peduncle latex

Scanning electron microscopy (SEM) will provide information of the morphology and size of the nanoparticles. FESEM micrograph presented in Fig. 7 suggests that the AgNPs were well dispersed without much aggregation and had a spherical shape. The average particle size is around $\sim 40 \mathrm{~nm}$. EDAX spectra shows (Fig. 8) strong signal for silver at the energy level of $3 \mathrm{keV}$ and also some of the weak signals, which might due to the present of C, K, O, Ca, Mg, Na and Si elements.

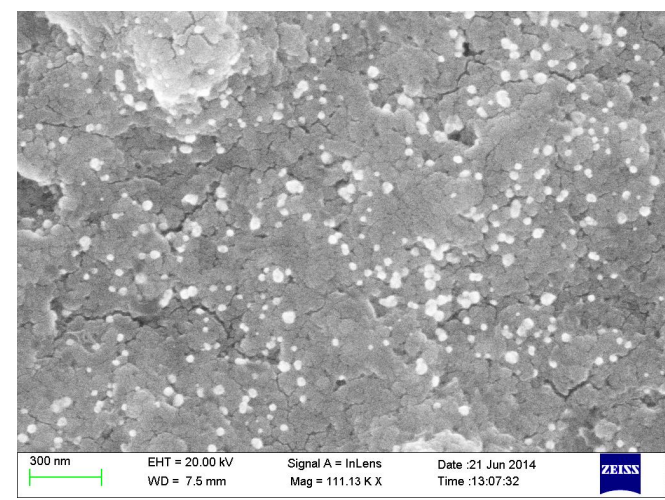

Fig. 7 FESEM image of synthesized AgNPs by using Musa paradisiaca peduncle latex

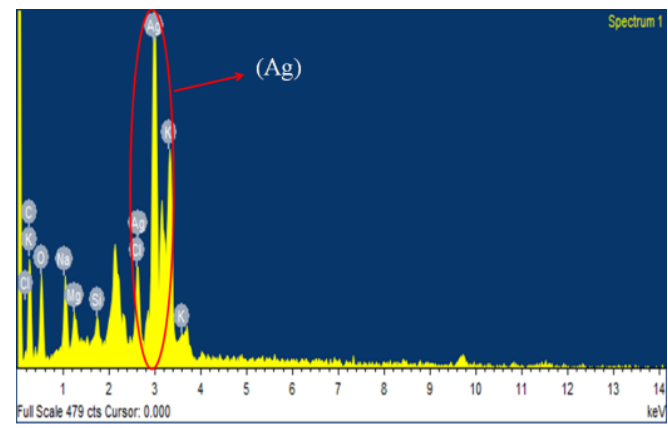

Fig. 8 EDAX spectrum of AgNPs synthesized by using Musa paradisiaca peduncle latex

TEM image of the AgNPs displayed in Fig. 9 reveals that the prepared AgNPs are dispersed and spherical in shape with some agglomeration at some places. Average size of the AgNPs was around $\sim 40 \mathrm{~nm}$. A selective area electron diffraction pattern depicted in Fig. 9 confirms the crystallinity of AgNPs. Particle size and distribution of AgNPs were also measured using particle size analyzer and the results are displayed in Fig. 10. The histogram showed that most of the particles are within $35 \mathrm{~nm}$, however, the size of the particles are ranged between 30-50 nm. 


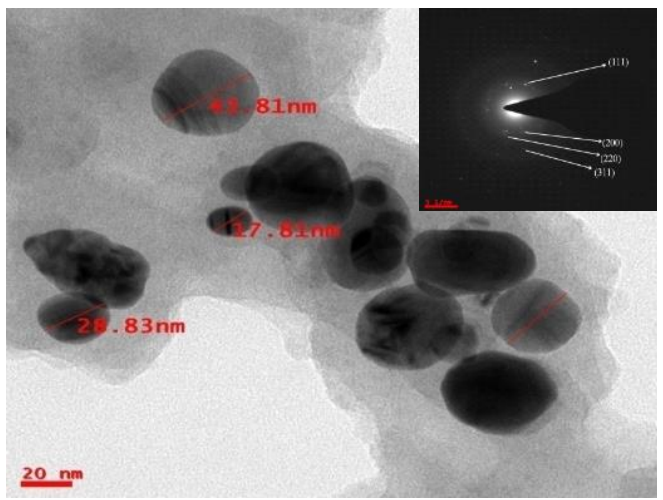

Fig. 9 HRTEM Image of synthesized AgNPs (inset: SAED pattern) by using Musa paradisiaca peduncle latex

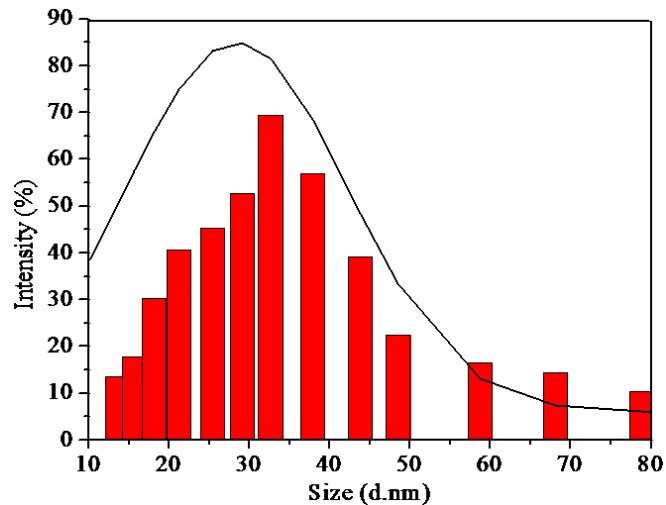

Fig. 10 Histogram of particle size distribution of synthesized AgNPs by using Musa paradisiaca peduncle latex

It is very difficult to find out exact mechanism behind the formation of nanoparticles by using natural phytochemical compounds because they contain diverse molecular structures, and need more detailed studies. In recent years some research groups have suggested possible mechanisms, while synthesizing gold and silver nanoparticles from various plants extracts such as geranium, neem, lemon grass and chickpea seeds etc. The proposed mechanism suggested by Mittel et al. [5] demonstrated that organic compounds such as alkaloids, flavonoids, phenolic compounds, triterpenes, saponins and tannins are responsible for the reduction and stabilization of MNPs. In this work, Musa paradisiaca peduncle latex also contained good amounts of these compounds, which can be effectively utilized for biosynthesis of AgNPs [26, 28, 34].

The phytochemical compounds such as, flavonoids, phenolics, triterpenes, saponins, and tannins etc., contains a high quantity of hydroxyl groups. The latex was added to $\mathrm{Ag}^{+}$solution, the $\mathrm{Ag}^{+}$reacts with the phytochemical complex and forms an intermediate and later converted to $\mathrm{Ag}^{0}$ particles followed by coalescence, cluster formation and growth of aggregation,. The phenolic groups present within latex are oxidized and converted to the quinone form. Difference in electrochemical potentials of $\mathrm{Ag}^{+}$and the phytochemicals is the driving force for the reaction. The AgNPs formation might be stabilized due to the presence of lone pair of electron and the $\pi$ electrons of the quinone structures [31].

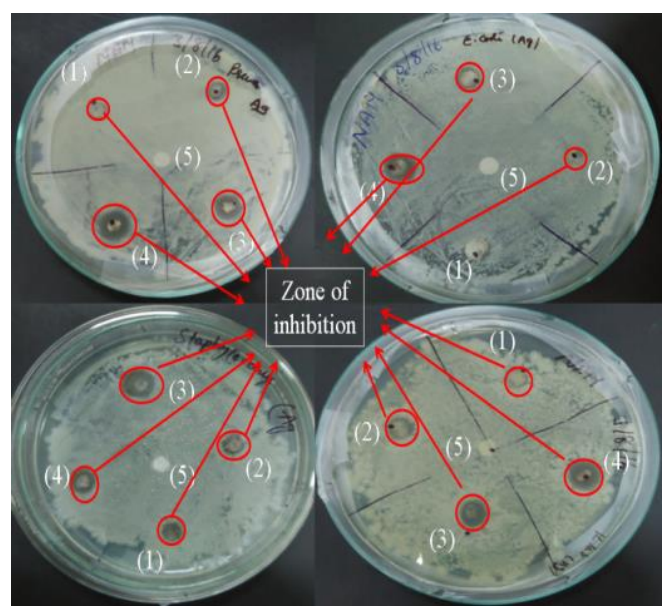

Fig. 11 Antimicrobial activity of synthesized AgNPs by using Musa paradisiaca peduncle latex against gram negative and gram positive bacterial culture https://doi.org/10.30799/jnst.151.18040511
Antimicrobial activity of synthesized AgNPs against Klebsiella, Staphylococcus aureus, Pseudomonas aeruginosa, and Escherichia coli $\mathrm{Sp}$, was studied and zone of inhibition (ZoI) results were presented in Table 3 and the images were displayed in Fig. 11. Five sterilized disks were placed in each plate. Disk nos. 1, 2 and 3 is filled with 10,20 and $30 \mu \mathrm{L}$ of $1 \mathrm{mg} / \mathrm{mL}$ aqueous dispersion of AgNPs. The disk no. 5 is filled with pure latex and disk 4 is filled with $30 \mu \mathrm{L}$ of $1 \%$ streptomycin (antibiotic) solution as standard. The results suggested that increase in concentration of AgNPs increases the inhibition towards the growth of bacteria. Compared to well no 3 and 4 which were filled with same quantity of silver nanoparticles and streptomycin, the antibiotic showed better ZoI values. No inhibition was observed in disk 5 which is filled with pure latex.

Table 3 Results of antimicrobial activity of synthesized AgNPs

\begin{tabular}{lllllll}
\hline S. No & Tested Pathogens & \multicolumn{6}{l}{ Zone of Inhibition $(\mathrm{mm})$} \\
\cline { 3 - 7 } & & $10 \mu \mathrm{L}$ & $20 \mu \mathrm{L}$ & $30 \mu \mathrm{L}$ & Streptomycin & Latex \\
\hline 1 & E.coli & 0 & 7 & 9 & 14 & 0 \\
2 & Staphylococcus aureus & 7 & 9 & 12 & 20 & 0 \\
3 & Pseudomonas aeruginosa & 0 & 8 & 10 & 13 & 0 \\
4 & Klebsiella & 7 & 9 & 10 & 15 & 0 \\
\hline
\end{tabular}

Many researchers were studied photocatalytic activity in the area of dye removal/degradation using AgNPs and their composites [35-37]. Compared to irradiation and other techniques, solar light irradiation technique was found to be faster in the decolorization of $\mathrm{MB}$ in the presence of AgNPs as a catalyst [38]. In this work, photo-catalytic activity for degradation of MB using synthesized AgNPs by solar irradiation technique was studied and the degradation results in terms of absorbance of dye solution were presented in Fig. 12.

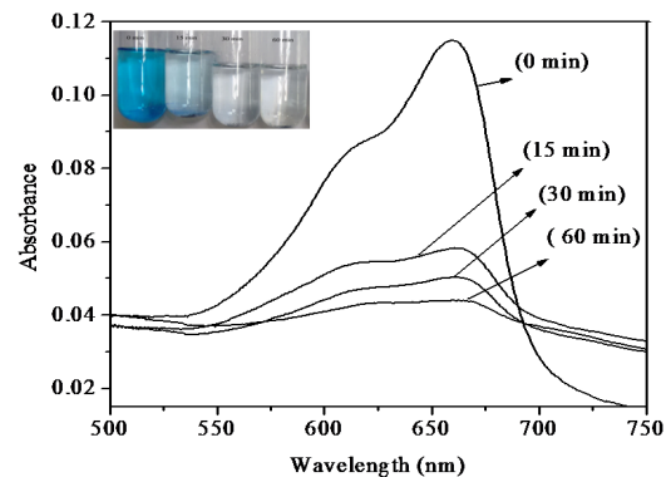

Fig. 12 UV - Vis spectra of dye removel/degradation of methyle blue solution using synthesized AgNPs by Musa paradisiaca peduncle latex (inset: Decolorization image of $\mathrm{MB}$ )

The characteristic absorbance of methylene blue solution was found to be $664 \mathrm{~nm}$. Removal/degradation of MB was visualized by decrease in peak intensity within $1 \mathrm{hr}$ under solar irradiation. Initially, the adsorption of AgNPs in MB solution is low and further increased with increase in time. This confirms that AgNPs acted as an electron transfer mediator between MB due to the electron relay effect [33]. The dye removal/degradation(\%) was calculated using the equation,

$$
\text { Dye degradation } \%=\left\lfloor\left(C_{0}-C_{t}\right) / C_{0}\right\rfloor \times 100
$$

where, $C_{0}$ is the initial concentration of the $\mathrm{MB}$ solution and $\mathrm{C}_{\mathrm{t}}$ is the concentration of the dye solution at time $t$ min of exposure to solar irradiation, and the results are shown in Fig. 13.

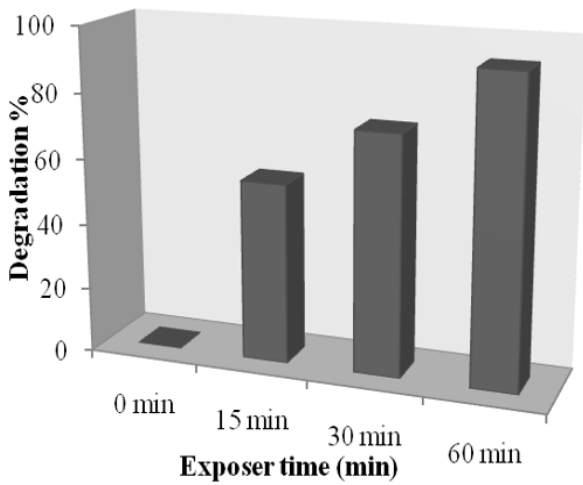

Fig. 13 Percent removal/degradation of MB dye at different exposure time using synthesized AgNPs by Musa paradisiaca peduncle latex 


\section{Conclusion}

Easy, rapid and well dispersed AgNPs were effectively synthesized by using Musa paradisiaca peduncle latex at room temperature. The effects of latex and $\mathrm{AgNO}_{3}$ concentrations and also the time on formation of AgNPs have also been studied and optimum concentration of $\mathrm{AgNO}_{3}$ and latex were found to be $2 \mathrm{mM}$ and $2.5 \%$, respectively in $50 \mathrm{~min}$ of reaction time. These AgNPs were well characterized and found to be spherical and dispersed well with average size of $\sim 40 \mathrm{~nm}$. These spherical shaped AgNPs exhibited good photo-catalytic activity under solar light irradiation for the degradation of MB dye and also showed good antimicrobial activity towards Staphylococcus aureus, Pseudomonas aeruginosa, Klebsiella and E. coli bacterial species.

\section{Acknowledgment}

Authors (BVKN and BVR) are greatly thankful to University Grants Commission for their financial support (F. No. 42-361/2013 (SR)). We are greatly thankful to Dr. Krishna Rao, Dept. of Chemistry, Y. V. University, Kadapa for providing UV-visible spectrophotometer and FTIR facility and also to Dr. Madakka, Dept. of Biotechnology \& Bio-informatics Y.V. University, Kadapa for her permission to carry out antimicrobial activity, and V. Rama Krishna, Dept. of Biotechnology \& Bio-informatics, Y.V. University, Kadapa for his permission to carry out quantitative and qualitative analysis.

\section{References}

[1] B. Kumar, K. Smita, Y. Angulo, L. Cumbal, Green synthesis of silver nanoparticles using natural dyes of cochineal, J. Clust. Sci. 27 (2016) 703-713.

[2] V.K. Sharma, R.A. Yngard, Y. Lin, Silver nanoparticles: Green synthesis and their antimicrobial activities, Adv. Colloid Interf. Sci. 145 (2009) 83-96.

[3] V.V. Makarov, A.J. Love, O.V. Sinitsyna, S.S. Makarova, I.V. Yaminsky, et al, Green nanotechnologies: synthesis of metal nanoparticles using plants, Acta. Nature 6 (2014) 35-37.

[4] C.L. Keat, A. Aziz, A.M. Eid, N.A. Elmarzugi, Biosynthesis of nanoparticles and silver nanoparticles, Bioresour. Bioprocess 2 (2015) 1-11.

[5] A.K. Mittal, Y. Chisti, U.C. Banerjee, Synthesis of metallic nanoparticles using plant extracts, Biotech. Adv. 31 (2013) 346-356.

[6] S. Sadia, T. Arifa, C. Yongsheng, Green synthesis of iron nanoparticles and their environmental applications and implications, Nanomater. 209 (2016) 1-26.

[7] A.M. Awwad, N.M. Salem, A.O. Abdeen, Green synthesis of silver nanoparticles using carob leaf extract and its antibacterial activity, Int. J. Indust. Chem. 4 (2013) 1-6

[8] Y. Park, Y.N. Hong, A. Weyers, Y.S. Kim, R.J. Linhardt, Polysaccharides and phytochemicals: a natural reservoir for the green synthesis of gold and silver nanoparticles, IET Nanobiotechnol. 5 (2011) 69-78.

[9] B. Venkataramana, S.S. Sankar, S.A. Kumar, V.K.B. Naidu, Synthesis of silver nanoparticles using Setaria italica (Foxtail Millets) husk and its antimicrobial activity, Res. J. Nanosci. Nanotech. 5 (2015) 6-15.

[10] S.S. Sana, V.R. Badineni, S.K. Arla, V.K.N. Boya, Eco-friendly synthesis of silver nanoparticles using leaf extract of Grewia flaviscences and study of their antimicrobial activity, Mater. Lett. 145 (2015) 347-350.

[11] K. Roy, C.K. Sarkar, C.K. Ghosh, Photocatalytic activity of biogenic silver nanoparticles synthesized using yeast (Saccharomyces cerevisiae) extract, Appl. Nanosci. 5 (2015) 953-959.

[12] B. Mohapatra, R. Kaintura, J. Singh, S. Kuriakose, S. Mohapatra, Biosynthesis of high concentration, stable aqueous dispersions of silver nanoparticles using Citrus limon extract, Adv. Mater. Lett. 6 (2015) 228-234.

[13] I. Fatimah, Green synthesis of silver nanoparticles using extract of Parkia speciosa Hassk pods assisted by microwave irradiation, J. Adv. Res. 7 (2016) 961-969.

[14] R. Sithara, P. Selvakumar, C. Arun, S. Anandan, P. Sivashanmugam, Economical synthesis of silver nanoparticles using leaf extract of Acalypha hispida and its application in the detection of Mn(II) ions, J. Adv. Res. 8 (2017) 561-568.

[15] M. Khatami, R. Mehnipor, M.H.S. Poor, G.S. Jouzani, Facile biosynthesis of silver nanoparticles using Descurainia sophia and evaluation of their antibacterial and antifungal properties, J. Clust. Sci. 27 (2016) 1601-1612.
[16] C. Shobana, B. Rangasamy, S. Surendran, R.K. Selvan, M. Ramesh, Green synthesized silver nanoparticles and their impact on the antioxidant response and histology of Indian major carp Labeo rohita, with combined response surface methodology analysis, J. Clust. Sci. 29(2018) 267-279.

[17] M.N. Gallucci, J.C. Fraire, A.P.V.F. Maillard, P.L. Paez, et al., Silver nanoparticles from leafy green extract of Belgian endive (Cichorium intybus L. var. sativus): Biosynthesis, characterization, and antibacterial activity, Mater. Lett. 197 (2017) 98-101.

[18] K. Muthu, S. Priya, Green synthesis, characterization and catalytic activity of silver nanoparticles using Cassia auriculata flower extract separated Fraction, Spectrochim. Acta A 179 (2017) 66-72.

[19] Y. He, X. Li, Y. Zheng, Z. Wang, Z. Ma, et al., Green approach of synthesizing of silver nanoparticles and their antibacterial and cytotoxicity activities, New J. Chem. 42 (2018) 2882-2888.

[20] Y. He, F. Wei, Z. Ma, H. Zhang, Q. Yang, et al., Green synthesis of silver nanoparticles using seed extract of Alpinia katsumadai, and their antioxidant, cytotoxicity, and antibacterial activities, RSC Adv. 7 (2017) 39842-3985.

[21] N. Jayaprakash, J.J. Vijaya, K. Kaviyarasu, K. Kombaiah, L.J. Kennedy, et al., Green synthesis of Ag nanoparticles using Tamarind fruit extract for the antibacterial studies, J. Photochem. Photobiol. B 169 (2017) 178-185.

[22] P. Nisha, S. Mini, Flavanoid rich ethyl acetate fraction of Musa paradisiaca inflorescence down-regulates the streptozotocin induced oxidative stress, hyperglycaemia and mRNA levels of selected inflammatory genes in rats, J. Funct. Foods 5 (2013) 1838-1847.

[23] V.D. Kappel, L.H. Cazarolli, D.F. Pereira, B.G. Postal, et al., Beneficial effects of banana leaves (Musa x paradisiaca) on glucose homeostasis: multiple sites of action, Rev. Bras. Farmacogn. 23 (2013) 706-715.

[24] L.B. Arun, A.M. Arunachalam, K.D. Arunachalam, S.K. Annamalai, K.A. Kumar, In vivo anti-ulcer, anti-stress, anti-allergic, and functional properties of gymnemic acid isolated from Gymnema sylvestre R Br, BMC Compl. Altern. Med. 14 (2014) 10-11.

[25] J. Parekh, S.V. Chanda, In vitro antimicrobial activity and phytochemical analysis of some Indian medicinal plants, Turk. J. Biol. 31(2007) 53-58.

[26] K.D. Arunachalam, L.B. Arun, S.K. Annamalai, A.M. Arunachalam, Potential anticancer properties of bioactive compounds of Gymnema sylvestre and its biofunctionalized silver nanoparticles, Int. J. Nanomed.16 (2015) 31-41.

[27] K.B. Ishnava, J.B. Chauhan, A.A. Garg, A.M. Thakkar, Antibacterial and phytochemical studies on Calotropis gigantia (L.) R. Br. Latex against selected cariogenic bacteria, Saudi J. Biol. Sci. 19 (2012) 87-91.

[28] S.V. Patil, H.P. Borase, C.D. Patil, B.K. Salunke, Biosynthesis of silver nanoparticles using latex from few Euphorbian plants and their antimicrobial potential, Appl. Biochem. Biotechnol. 167 (2012) 776-790.

[29] L. Ciesla, J. Kryszen, A. Stochmalb, W. Oleszekb, M. Waksmundzka-Hajno, Approach to develop a standardized TLC-DPPH test for assessing free radical scavenging properties of selected phenolic compounds, J. Pharm. Biomed. Anal. 70 (2012) 126-135.

[30] R.M. Mariita, C.K.P.O. Ogol, N.O. Oguge, P.O. Okemo, Antitubercular and phytochemical investigation of methanol extracts of medicinal plants used by the samburu community in Kenya, Trop. J. Pharm. Res. 9 (2010) 379-385.

[31] T.N.J.I. Edison, Y.R. Lee, M.G. Sethuraman, Green synthesis of silver nanoparticles using Terminalia cuneata and its catalytic action in reduction of direct yellow-12 dye, Spectrochim. Acta A 161 (2016) 122-129.

[32] R.S. Phatak, A.S. Hendre, Sunlight induced green synthesis of silver nanoparticles using sundried leaves extract of Kalanchoe pinnata and evaluation of its photocatalytic potential, Der Pharmacia Lett. 7 (2015) 313324.

[33] H. Bar, D. Kr. Bhui, G.P. Sahoo, P. Sarkar, S.P. De, A. Misra, Green synthesis of silver nanoparticles using latex of Jatropha curcas, Colloid. Surf. A 339 (2009) 134-139.

[34] K.B. Narayanan, N. Sakthivel, Extracellular synthesis of silver nanoparticles using the leaf extract of Coleus amboinicus Lour, Mater. Res Bull. 46 (2011) 1708-1713.

[35] M. Busila, Ibanescu, V. Musat, T. Textor, V. Badilita, B. Mahltig, Photocatalytic and antimicrobial $\mathrm{Ag} / \mathrm{ZnO}$ nanocomposites for functionalization of textile fabrics, J. Alloys Compd. 610 (2014) 244-249.

[36] M.V. Roldan, D.O. Paula, Y. Castro, A. Duran, P. Faccendini, Photocatalytic and biocidal activities of novel coating systems of mesoporous and dense $\mathrm{TiO}_{2-}$ anatase containing silver nanoparticles, Mater. Sci. Eng. C 43 (2014) 630-640.

[37] A.B. Djurisic, Y.H. Leunga, A.M.C. Ngab, Strategies for improving the efficiency of semiconductor metal oxide photocatalysis, Mater. Horiz. 1 (2014) 400-410.

[38] G.G. Selvam, K. Sivakumar, Phycosynthesis of silver nanoparticles and photocatalytic degradation of methyl orange dye using silver (Ag) nanoparticles synthesized from Hypnea musciformis (Wulfen) J.V. Lamouroux, Appl. Nanosci. 5 (2015) 617-622. 